titulado Secretum philosophorum; el artículo de Spike Bucklow, del Hamilton Kerr Institute, sobre el porqué de la existencia en muchos recetarios de recetas imposibles de llevar a la práctica; sobre estudios de diferentes fuentes escritas, como un manual rumano manuscrito del siglo XVIII sobre iluminación (Urescu y Ciovica), manuales de mapas militares en España (Kroustallis), elaboración de moldes para relieves de estaño según evidencias documentales de los siglos XIII a XVI (Nadolny), o un manuscrito portugués del siglo XVIII (Freitas, Claro, Melo, Casanova y Moura); reconstrucción de recetas a partir de textos (Miguel, Claro, Lopes y Melo; Neven); estudios sobre la técnica de artistas a partir de documentación de diferente índole, como Rubens (Dubois), Oudry (Phenix, Doherty, Schönemann y Rizo), Kupelwieser (Eyb-Green, Baatz y Kitlitschka), Whistler (Hermens y MacDonald) o Smith (Mulholland); el estudio de los materiales pictóricos contenidos en un gabinete de de 1704 (Wagner), de pigmentos del siglo XIX (Kutzke y Oltrogge) o las entrevistas a artistas como fuente documental según experiencias con artistas finlandeses de finales del siglo XX (Kyllonen-Kunas). Toda esta serie de contribuciones vienen encabezadas por la conferencia magistral de Manfred Lautenschlager, especialista en historia medieval de la Universidad alemana de Erlangen, que trata sobre un texto anónimo alemán de siglo XV de tipo moralista que pasa revista a los distintos oficios, interesante exponente de cómo se puede encontrar información muy valiosa en textos no directamente relacionados con las técnicas artísticas.

Como sucede en los anteriores encuentros, la selección de ponencias se ha llevado bajo un criterio de adecuación rigurosa a una metodología que se está convirtiendo en su marca de identidad y que gradualmente está conformando un área disciplinar de características propias, como son el recurso a las fuentes convencionales y no convencionales, la interpretación de estas fuentes bajo distintos métodos (filológicos, codicológicos, históricos, etc.) y la comprobación de datos con métodos científicos mediante técnicas instrumentales de caracterización de materiales o reconstrucción de recetas. La variedad de temas y el rigor de los estudios presentados convierten a esta publicación, de igual modo que las otras de la serie, en una referencia bibliográfica imprescindible para la sumergirse en el estudio de la tecnología del arte.

Rocío Bruquetas

Instituto del Patrimonio Cultural de España

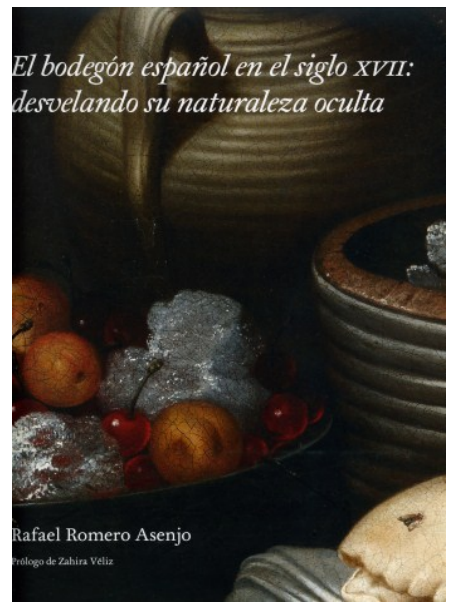

\title{
El bodegón español en el siglo XVII: desvelando su naturaleza oculta
}

Rafael Romero Asenjo

Publicado por I \& R Restauración y Estudios Técnicos de Pintura de caballete

Madrid, 2009

431 páginas, $31 \times 24,5 \mathrm{~cm}$.

ISBN: 978-84-613-6966-9

El desarrollo de las técnicas instrumentales aplicadas al estudio de las obras de arte ha ido configurando un campo de conocimiento cada vez más apreciado por el mundo de la historia del arte. Generalmente estos estudios se realizan en laboratorios ligados a instituciones museísticas o centros públicos de conservación del patrimonio. En este caso ha partido de la iniciativa particular de un profesional independiente interesado en ordenar, investigar, analizar y difundir la información 
reunida a lo largo de su dilatada vida profesional como restaurador. Hace varios años Rafael Romero montó junto con Adelina Yllán $I \& R$ restauración y estudios técnicos de Pintura de caballete, un centro privado que, como su nombre indica, no solo se ha dedicado a la restauración de pintura, sino también a realizar estudios desde el punto de vista técnico (radiografía, reflectografía y otros estudios físicos, así como análisis de materiales con diversas técnicas instrumentales) por encargo de instituciones o particulares. Conscientes de la valiosísima información que contiene toda esta documentación para el conocimiento de la pintura española, una buena parte de su dedicación profesional se ha dirigido a investigar y analizar con mayor profundidad algunas obras o aspectos de su ejecución técnica, cuyo fruto se ha plasmado en una diversas publicaciones anteriores, bien en forma de recopilación de sus trabajos (Ciencia es Esencia. Cuadernos de Conservación y Tecnología del Arte, 2008), bien en colaboraciones para revistas especializadas y congresos.

En este caso Romero ha reunido una amplísima información sobre naturalezas muertas españolas del siglo XVII pertenecientes a una extenso catálogo de más de 30 artistas, entre los que se encuentran Juan Sánchez Cotán, Alejandro de Loarte, Juan van der Hamen, Francisco Barrera, Juan de Espinosa, Francisco de Zurbarán, Lucas Valdés, Antonio de Pereda o José de Arellano. Como señala en la introducción, su objetivo era aportar unas líneas generales sobre los procedimientos pictóricos empleados por los artistas dedicados a este género en las distintas escuelas peninsulares del siglo XVII, un propósito que de esta forma global no se había emprendido con anterioridad. Los estudios precedentes sobre bodegones españoles con los que podía contar se reducían a un número limitado de estudios puntuales realizados con motivo de restauraciones.

Prologa la obra Zahira Véliz, historiadora y restauradora norteamericana cuyos estudios sobre la tratadística española del Siglo de Oro y sobre la técnica de nuestros grandes maestros han constituido importantes hitos para el conocimiento de nuestra pintura, no solo por su personales contribuciones científicas a este campo sino por el reconocimiento exterior que la literatura técnica española ha logrado gracias a sus traducciones al inglés.

En un primer capítulo introductorio el autor expone los motivos y antecedentes de los que ha partido para iniciar sus estudios, y en el que ya incorpora algunas conclusiones de los resultados. Organiza el cuerpo de la obra mediante un catálogo de artistas distribuidos según escuelas (Castilla, Madrid, Andalucía y Valencia) y etapas cronológicas (primera y segunda mitad del siglo XVII), para finalizar con algunos maestros anónimos de difícil ubicación geográfica. Cada capítulo se inicia con una descripción de las características técnicas generales observadas en las obras de esa etapa y escuela: preparación de los soportes, primeras fases del proceso compositivo, pigmentos, aglutinantes y barnices. En el espacio reservado para cada artista incluye unas referencias biográficas y estilísticas y una síntesis de su producción artística, para pasar a exponer sus conclusiones particulares sobre la técnica de cada una de las obras estudiadas, a partir de los resultados aportados por las técnicas instrumentales de análisis de materiales y por los estudios físicos. En este catálogo vuelca toda la información reunida en los análisis realizados en su propio estudio o en colaboración con otros profesionales, como Asunción Millán, de la Universidad Autónoma de Madrid, para análisis SEM-EDX, Enrique Parra, de la Universidad Alfonso X el Sabio, para la microscopía, análisis SEM-EDX, GC-MS y FTIR, o su socia en Icono I\&R, Adelina Yllán, para el tratamiento de las imágenes radiográficas y reflectografía de infrarrojos.

En el catálogo no solo aborda obras que han pasado por su estudio para ser restauradas, también incorpora documentos radiográficos y análisis realizados sobre otras pertenecientes a distintas instituciones españolas y extranjeras a los que ha tenido acceso para completar su trabajo de investigación. Completa el estudio con unos utilísimos apéndices que recogen en forma de gráficos la información específica sobre tipología de soportes de tela, aglutinantes y pigmentos utilizados en las obras de referencia. 
Pero la aportación del autor no se limita a una mera descripción de resultados, por otro lado muy minuciosa y completa, sino que desarrolla una interpretación en clave histórica que relaciona los datos obtenidos con las técnicas de otras escuelas europeas y con la información de los tratados de los siglos XVII y XVIII. La contribución de Rafael Romero es una excelente oportunidad no solo para conocer una interesantísima documentación técnica gracias a la magnífica reproducción de las imágenes y al trabajo de conexión de datos facilitado por el autor; también nos permite dirigir una mirada de conjunto a través de su personal análisis sobre este género pictórico tan poco estudiado desde el punto de vista técnico.

Su trabajo se identifica, pues, con este nuevo campo de conocimiento que habitualmente llamamos "estudios técnicos de obras de arte" y que, como indica el autor en la introducción, en el mundo anglosajón se ha acuñado como technical art history, un campo que resulta cada vez más indispensable para complementar los enfoques tradicionales de la historia del arte. Confiamos que la labor emprendida por Rafael Romero se vea continuada por sucesivas investigaciones y publicaciones que enriquezcan este campo de estudio de la pintura española.

Rocío Bruquetas

Instituto del Patrimonio Cultural de España

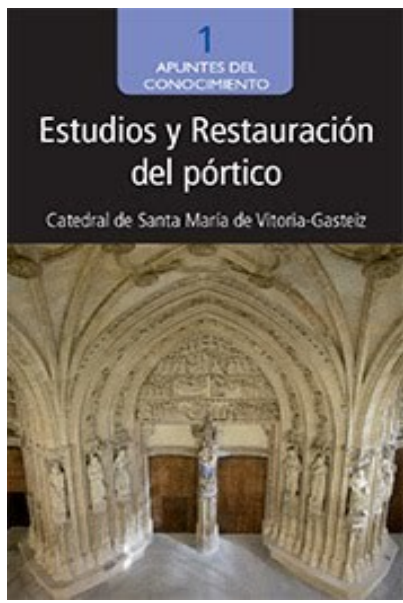

\title{
Estudios y Restauración del pórtico. Catedral de Santa María de Vitoria-Gasteiz
}

\author{
Mercedes Cortazar, Diana Pardo y Dolores Sanz
}

Edita: Santa Maria Katedrala Fundazioa - Fundación Catedral Santa María

Colección «Apuntes del Conocimiento»

Vitoria - Gasteiz, 2009

291 páginas, ilustraciones, gráficos, figuras, $24 \times 17 \mathrm{~cm}$.

ISBN : 978-84-613-5473-3

El ejemplo de la Restauración de la Catedral de Santa María de Vitoria-Gasteiz es hoy conocido por casi todos los especialistas en Conservación-Restauación de monumentos. Se ha convertido en un ejemplo y referente obligado por su enfoque metodológico, dentro de los planes directores de catedrales, y por su repercusión en la afluencia de turismo cultural, "turismo del conocimiento" como les gusta decir a los responsables de la Fundación Catedral Santa María, que ayuda a la sostenibilidad y al desarrollo del casco histórico de la ciudad de Vitoria-Gasteiz. Tanto es así que su programa de visitas "abierto por obras" ha sido imitado en otros muchos proyectos de intervención, en España y en el extranjero, aunque con diferente fortuna.

Es precisamente de esta filosofía de "restauración abierta", que surge como consecuencia de un convencimiento profundo de la función social del Patrimonio y de la necesidad de "socializar el conocimiento", de devolver a la sociedad la información y los conocimientos que se van desprendiendo de los múltiples trabajos, investigaciones y estudios interdisciplinares que se están llevando a cabo en la Catedral de Santa María, mediante una amplia labor de divulgación con visitas guiadas, conferencias, página Web de la Fundación Catedral Santa María, de la que nace también la 